\title{
The effect of a herbal formulation on the incidence and severity of upper respiratory symptoms in healthy volunteers: an open-label, randomised controlled clinical trial
}

\section{Goonaratna ${ }^{1}$, M R Sooriyarachchi ${ }^{2}$}

(Index words: upper respiratory symptoms, short form WURSS-21, herbal medicinal product)

\begin{abstract}
Introduction Many traditional preparations with varying combinations of herbs have been used for over 1500 years to treat upper respiratory ailments, and reduce their incidence and severity. Link Samahan ${ }^{\circledast}$ is a formulation containing the extract of 14 such medicinal plants.
\end{abstract}

Objectives To test the efficacy of Link Samahan ${ }^{\circledast}$ in reducing the incidence and severity of upper respiratory symptoms in consenting healthy volunteers.

Setting MAS Linea Aqua, a factory with over 3000 employees, having its own health care centre with a qualified matron and visiting medical officers.

Methods 956 healthy volunteers took daily either one sachet of Link Samahan ${ }^{\circledast}$ in hot water (test group, $\mathrm{n}=465$, mean age $29.5 \pm 7.7$ years, women 418 ) or only plain tea (control group $\mathrm{n}=491$, mean age $29.7 \pm 7.9$, women 448), for 84 consecutive days, and recorded the incidence and severity of 15 upper respiratory symptoms daily in a purpose-designed form.

Results At the end of 84 days, when compared to the control group, the average incidence of symptoms in the test group showed highly significant reductions at $p<0.001$ for 6 symptoms and at $p<0.005$ for 3 symptoms, and at $p<0.05$ for the remaining 6 . Reduction of average incidence over time also was highly significant $(p<0.001)$ for 2 symptoms and $(p<0.005)$ for 7 , and significant $(p<0.05)$ for 4 symptoms, but only marginal for the balance 2 . Severity was significantly reduced $(p<0.05)$ for 7 symptoms, and reduced also for the other 8 according to descriptive analysis, though not significant at the $5 \%$ level.

Conclusions The results indicate that Link Samahan ${ }^{\oplus}$ taken as one sachet daily significantly reduces average incidence, incidence over time, and severity of 15 upper respiratory symptoms in healthy adults.

Ceylon Medical Journal 2012; 57: 19-32

\section{Introduction}

Many herbal preparations have been used as decoctions in the treatment and prevention of upper respiratory tract ailments with catarrhal symptoms in Ayurveda and in our island's unique Desheeya Chikitsa for over 15 centuries. The most widely used plants include Adhatoda vasica, Alpinia galanga, Carum copticum, Coriandrum sativum, Coscinium fenestratum, Cuminum cyminum, Evolvulus alsinoides, Glycyrrhiza glabra, Hedyotis corymbosa, Piper longum, Piper nigrum, Premna herbacea, Solanum xanthocarpum, and Zingiber officinale. Link Samahan ${ }^{\circledast}$ is an over-thecounter standardised preparation made from these plants in the proportions advised by a panel of senior and clinically experienced Ayurveda physicians. The concentrated oleoresin extract of the plants is wet granulated, dried and formulated as water-soluble aromatic granules marketed in triple-laminated sachets, each containing 4 g. Link Samahan ${ }^{\circledast}$ (test herbal product) may be taken dissolved in hot water, or in a beverage such as tea or coffee.

The test herbal product has been widely used for over 15 years, both in Sri Lanka and overseas. However, its efficacy in reducing the incidence and severity of upper respiratory symptoms has not been previously tested in a clinical trial.

\section{Methods}

We designed an open-label, randomised, controlled clinical trial to test its efficacy in healthy volunteers. The assessors of efficacy (i.e. data entry operators and statisticians) were blinded regarding the group (i.e. test or control) to which participants belonged. A placebo could not be used although the packeting technology was readily available as the aroma of this herbal product is instantly identifiable and cannot be masked or replicated by a placebo. The healthy volunteers were selected from employees of MAS Linea Aqua, a garment factory with high ethical standards of worker welfare.

${ }^{1}$ Emeritus Professor of Physiology, University of Colombo and Registrar, Ceylon Medical College Council; ${ }^{2}$ Professor, Department of Statistics, University of Colombo, Sri Lanka.

Correspondence: CG, e-mail: <si7np5e@gmail.com>. Received 30 November 2011 and revised version accepted 11 January 2012. Competing interests: CG is an Advisor on Clinical Research to Link Natural Products (Pvt) Ltd. 
After initial meetings with the senior management and human resource managers of the factory, several meetings were held with groups of workers to explain the objectives and procedural details of our study. From 1311 consenting volunteers 956 (465 and 491 in the test and control groups respectively) were enrolled in the study. The exclusion criteria were actual or suspected pregnancy, lactation, significant systemic disease, and a history of bronchial asthma. The inclusion criteria were age between 20 and 50 years, and willingness to give witnessed and written informed consent to participate in the clinical trial for 84 consecutive days.

At the study's completion, a further 155 were excluded from analysis (79 and 76 respectively from the test and control groups) because they had not completed the forms properly for varying periods, so only 801 participants (386 from the test and 415 from the control group respectively) were included for data entry and statistical analysis.

The evaluative instrument used in our study is the short form Wisconsin Upper Respiratory Symptom Survey (WURSS - 21), the performance of which has been validated for reliability, responsiveness, importance-topatients and convergence with other measures [1,2]. Of the 21 symptoms in WURSS - 21, we selected 15 as being most appropriate for our cultural background by focus group discussion and consultation with senior Ayurveda physicians. The selected symptoms are given in Table 1.

\section{Table 1. Symptoms selected from WURSS - 21 for our study}

\section{Excess sneezing}

2. Watery nasal discharge

3. Nasal congestion

4. Itching of eyes and tearing

5. Scratchy throat

6. Throat pain

7. Hoarseness of voice

8. Feverishness

9. Cough

10. Tiredness

11. Headache

12. Itchy ears, blocked ears

13. Loss of appetite

14. Body pains

15. Difficulties in daily activities
The 15 selected symptoms were translated into Sinhala (there were no Tamil participants) and backtranslated into English by language experts before inclusion in the form that was to be filled by all participants in both test and control groups daily (Figure 1). The forms were colour-coded for enhanced clarity, and collected every week from participants by members of the research team.

Allocation of participants to the test or control group was randomised by each volunteer selecting from a box containing identical sealed envelopes with a card inside labelled "Test" or "Control", opened in view of the volunteer. The flow of participants through the study is given in Figure 2.

A "cold day" was defined as one where an individual had 7 or more of the symptoms listed [1,2]. From a pilot study among factory workers the probability of a "cold day" was estimated as 0.1949 for the control group. Setting the significance level at $5 \%$, the power of the study at $90 \%$, and the reference improvement in the test group to be $25 \%$ that of the control group, and employing a recognised sample size calculation for a binary response [3], 704 was the resultant total number for both groups of participants. The number recruited was 1020 , to compensate for anticipated "last moment" decisions to refrain from participation (63/1020, 6.2\% in our study), and failure to fill the forms properly $(155 / 956,17.6 \%)$ (Figure 2).

The average incidence of symptoms in each group was estimated as follows. Initially, for each participant the percentage of days (out of the total of 84 days) with a given symptom was determined. This was averaged over all participants in each group. The significance of the difference in incidence between the control group and the test group was tested using a hypothesis test based on the binominal approximation to the normal.

To compare the performance of each group over time during the entire 12-week period of the study, the average percentage of incident-free days for each week was calculated for each symptom, from the responses of each individual participant.

Figures 3 - 6 show descriptive trend lines for incidence of 4 upper respiratory symptoms for the test and control groups, where the vertical axis indicates the percentage number of days participants did not have the particular symptom during each week, through the entire period of 12 weeks. Trend lines for all 15 symptoms are similar to the four depicted here. All are approximately linear, and in all 15 the trend line for the test group is steeper than that for the control group, indicating that there is an improvement over time of the particular symptom's incidence, in the former group. To confirm this, a general linear model must be fitted to the data, but doing so requires the assumption that the response variable, namely, the average number of days without a given symptom over time, follows a normal distribution for both test and control groups, over 12 weeks [4]. 
The relevant general linear model [4] can be expressed as:

$$
Y_{i}=a+t_{i}+g_{j}+(t \cdot g)_{i j}+e_{i}
$$

Where, $\mathrm{i}=1$, to $12 ; \mathrm{j}=1,2 ; \mathrm{a}=$ overall mean; $\mathrm{Y}_{\mathrm{i}}=$ average incidence over week $i ; t_{i}=$ effect of $i^{\text {th }}$ week; $g_{j}=$ effect of $j^{\text {th }}$ group; (t.g $)_{i j}=$ the combined effect of $i^{\text {th }}$ week and $j^{\text {th }}$ treatment group; and $e_{j}=$ error term corresponding to the $\mathrm{i}^{\text {th }}$ observation.

To verify the requisite assumption normal probability plots were composed for all 15 symptoms for both groups. The four probability plots corresponding to the 4 symptoms in figures $3-6$, are shown in figures $7-10$. It is clear from figures 7 - 10 that the average percentages of symptom-free days for the 12 weeks, for both groups, are approximately linear and fall well within the $95 \%$ confidence limits. The pattern of all other probability plots were similar to those shown as examples in figures 7 - 10, over the entire study period of 12 weeks.

Since normal probability plots indicated that the responses had an approximate normal distribution, and descriptive trend lines showed that the trends were approximately linear, the general linear model shown above was fitted with the response variable being the average incidence over the total number of participants in each group, and the exploratory variables being the week (going from 1 to 12), the treatment group (going from 1 to 2), and their interaction [4]. The main focus of interest here was the interaction between each week and group, and testing whether there was a steeper trend over 12 weeks in the test group when compared to the control group.

For assessment of severity of the symptoms the response of each participant for each of the 15 symptoms in both groups was coded as: $0=$ no symptom, $1=$ mild symptom, 2 = moderate symptom, and $3=$ severe symptom (Figure 1). Differences in proportions between the control and test groups were tested as in the comparison performed for average incidence (see above), the only difference being that in comparing severity, three proportions were calculated (viz. mild versus no symptom, moderate versus no symptoms, and severe versus no symptom).

Our study has been approved by the Sri Lanka Medical Association's Ethical Review Committee (ERC/ 10-14), and registered by the Sri Lanka Clinical Trials Registry (SLCTR/2011/001).

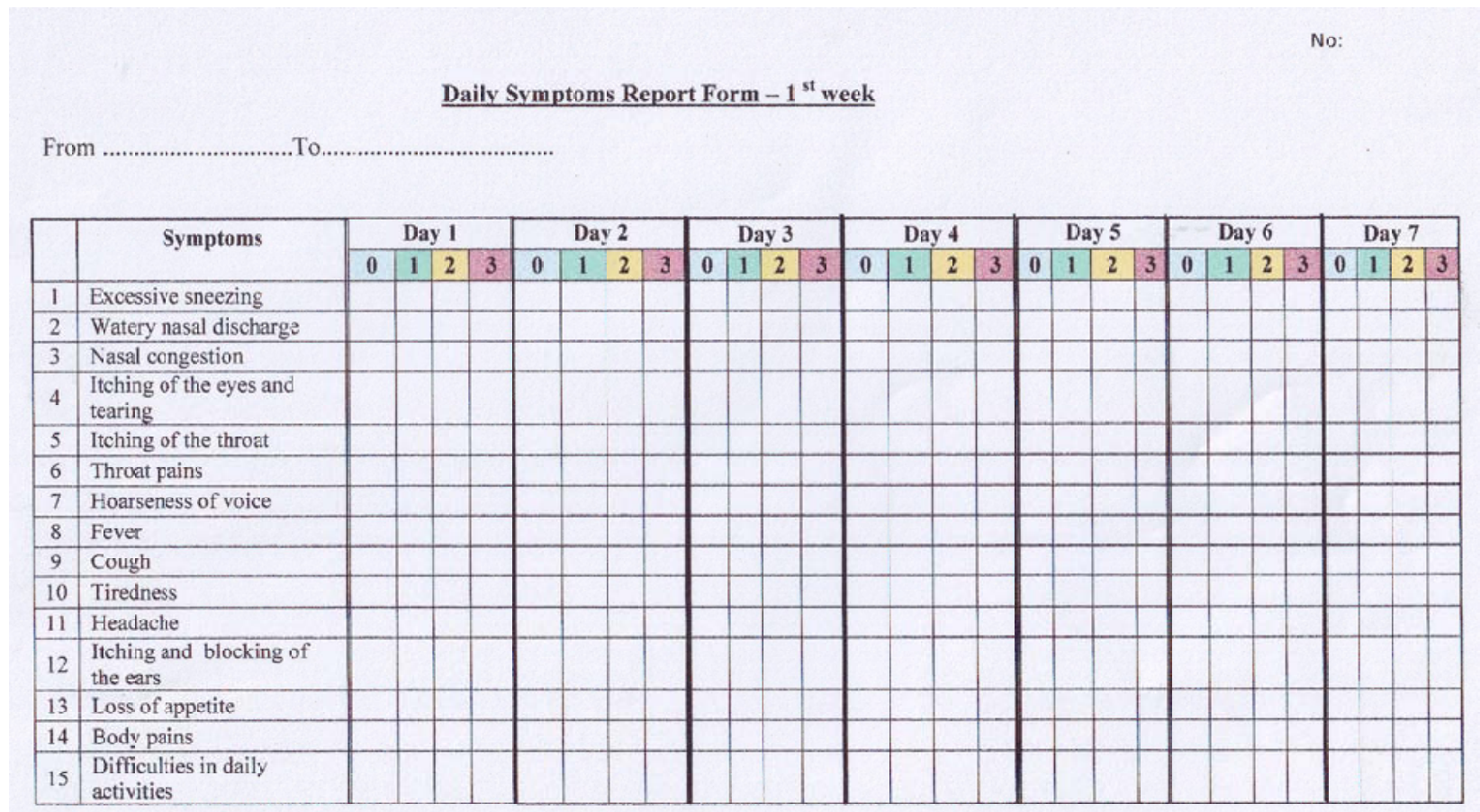

\begin{tabular}{|c|c|cc|}
\hline Not Sick & Mildly & Moderately & Severely \\
0 & 1 & 2 & 3 \\
\hline
\end{tabular}

Mark $\sqrt{ }$ in relevant cage

Figure 1. Colour-coded response form. This was translated into Sinhala for participants' use. 


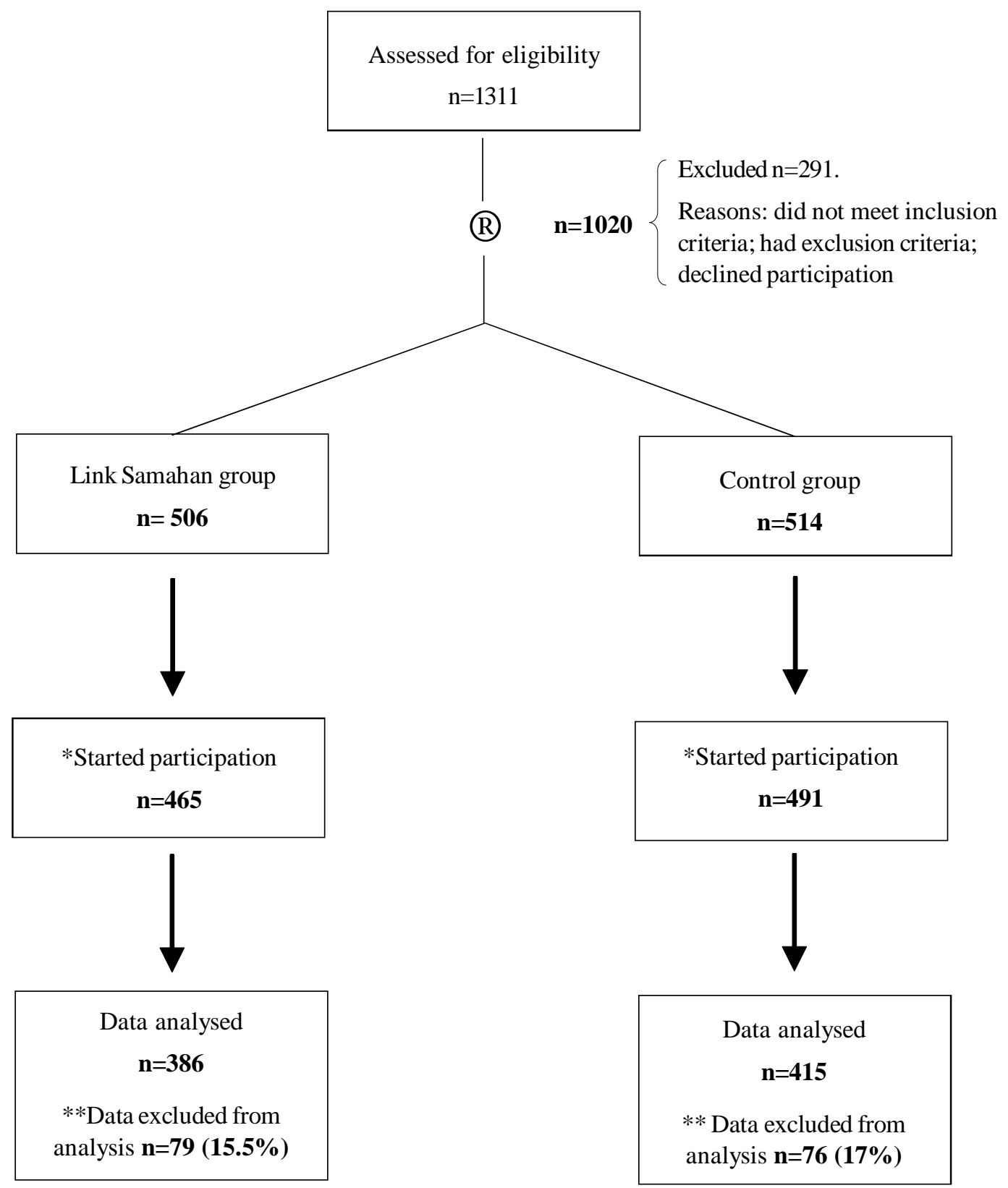

** Forms incompletely filled.

*Did not start participation; test group $n=41$, control group $n=23$

(B) - Randomisation

Figure 2. Flow of participants through the study. 


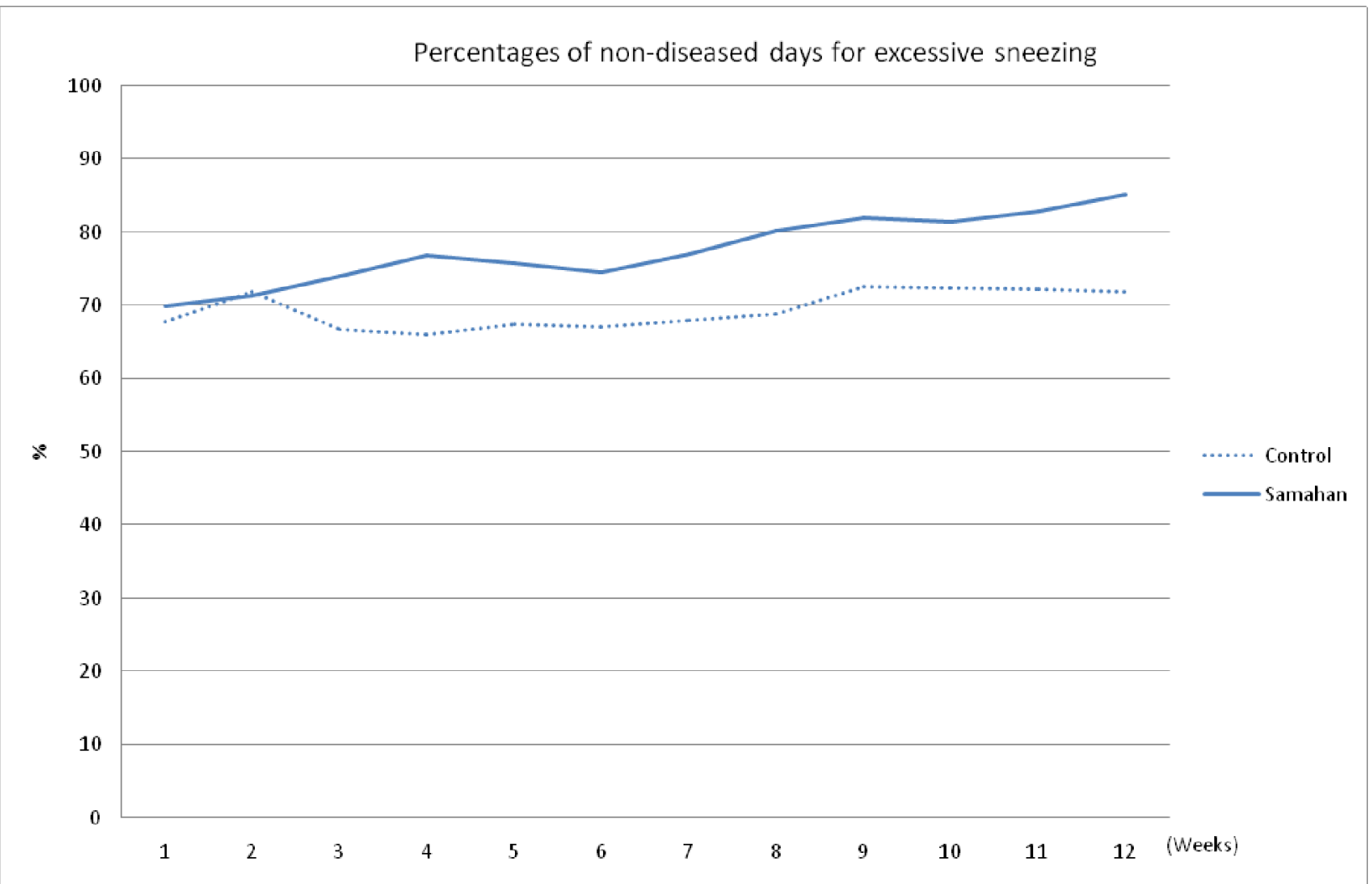

Figure 3. Percentage of days with no excessive sneezing over time for the two groups.

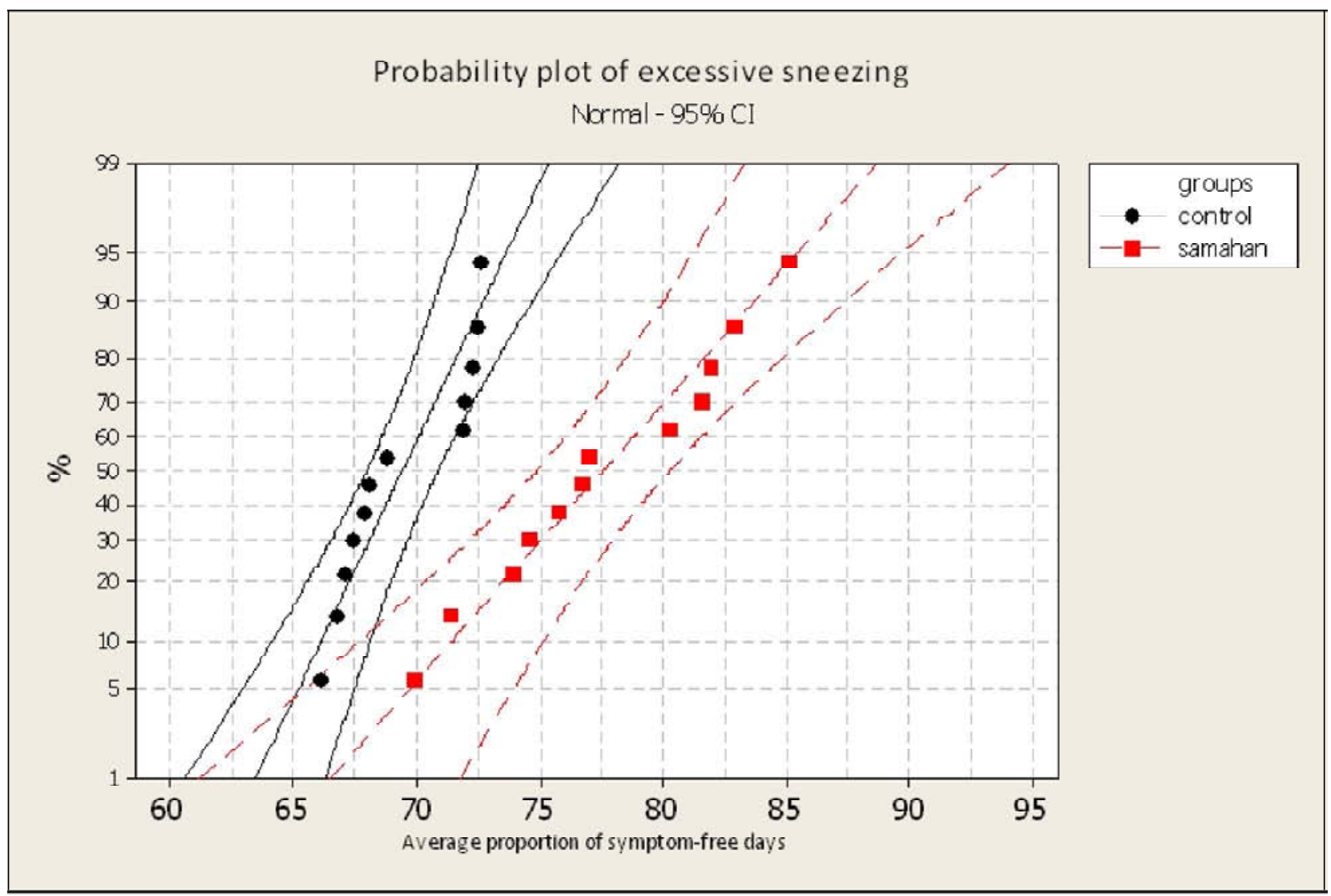

Figure 7. Normal probability plot for excessive sneezing for the two groups. 


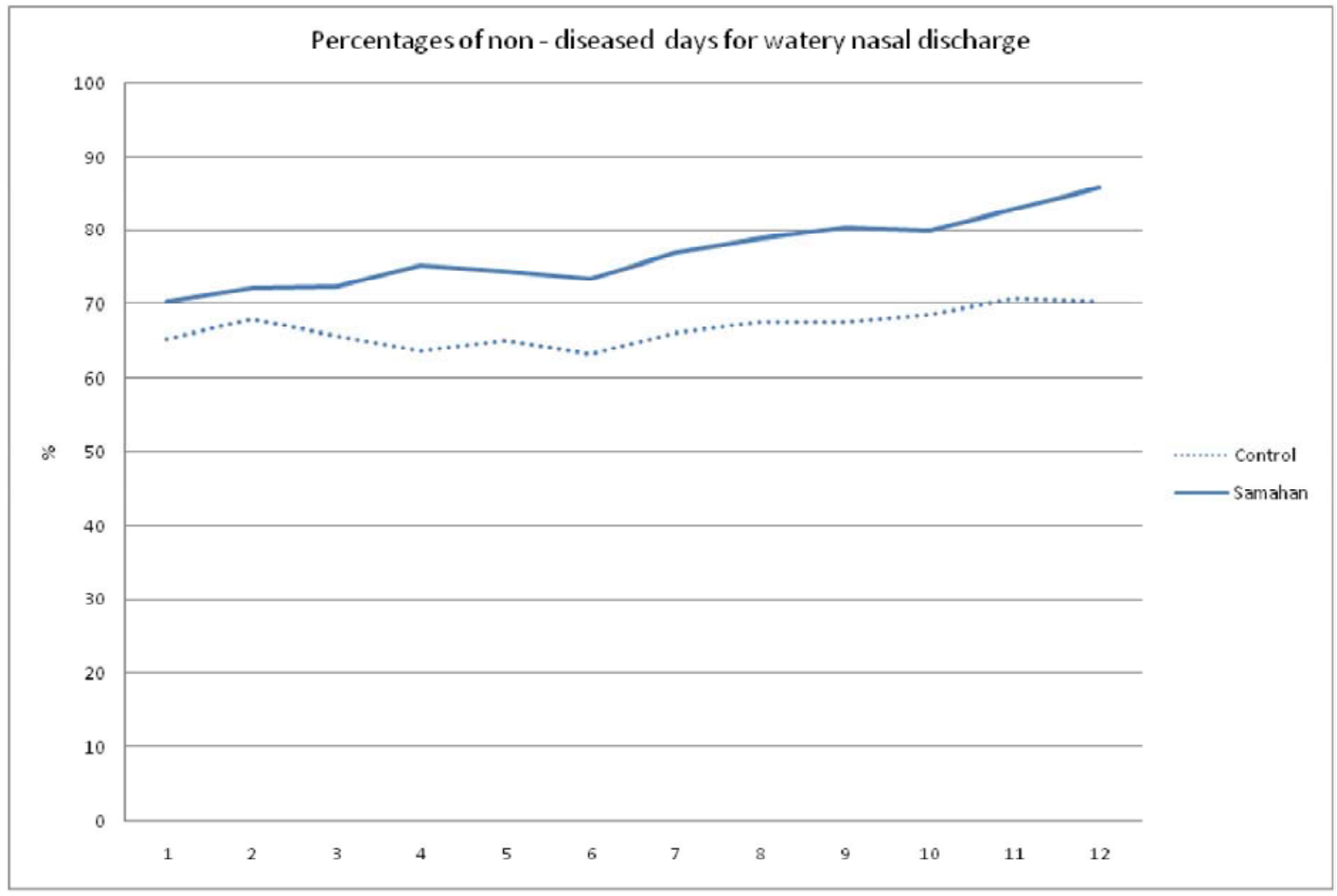

Figure 4. Percentage of days with no watery nasal discharge over time for the two groups.

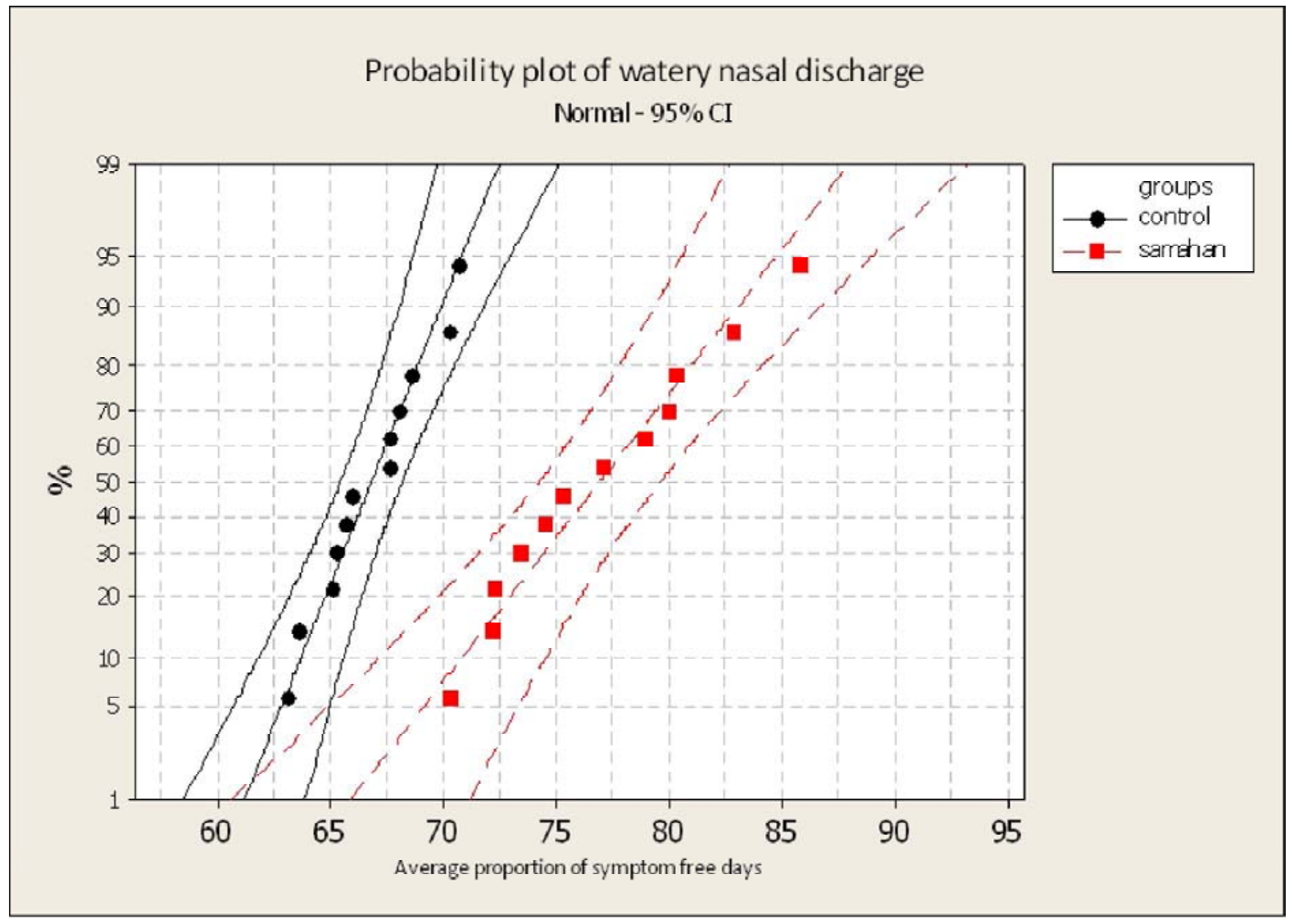

Figure 8. Normal probability plot for watery nasal discharge for the two groups. 


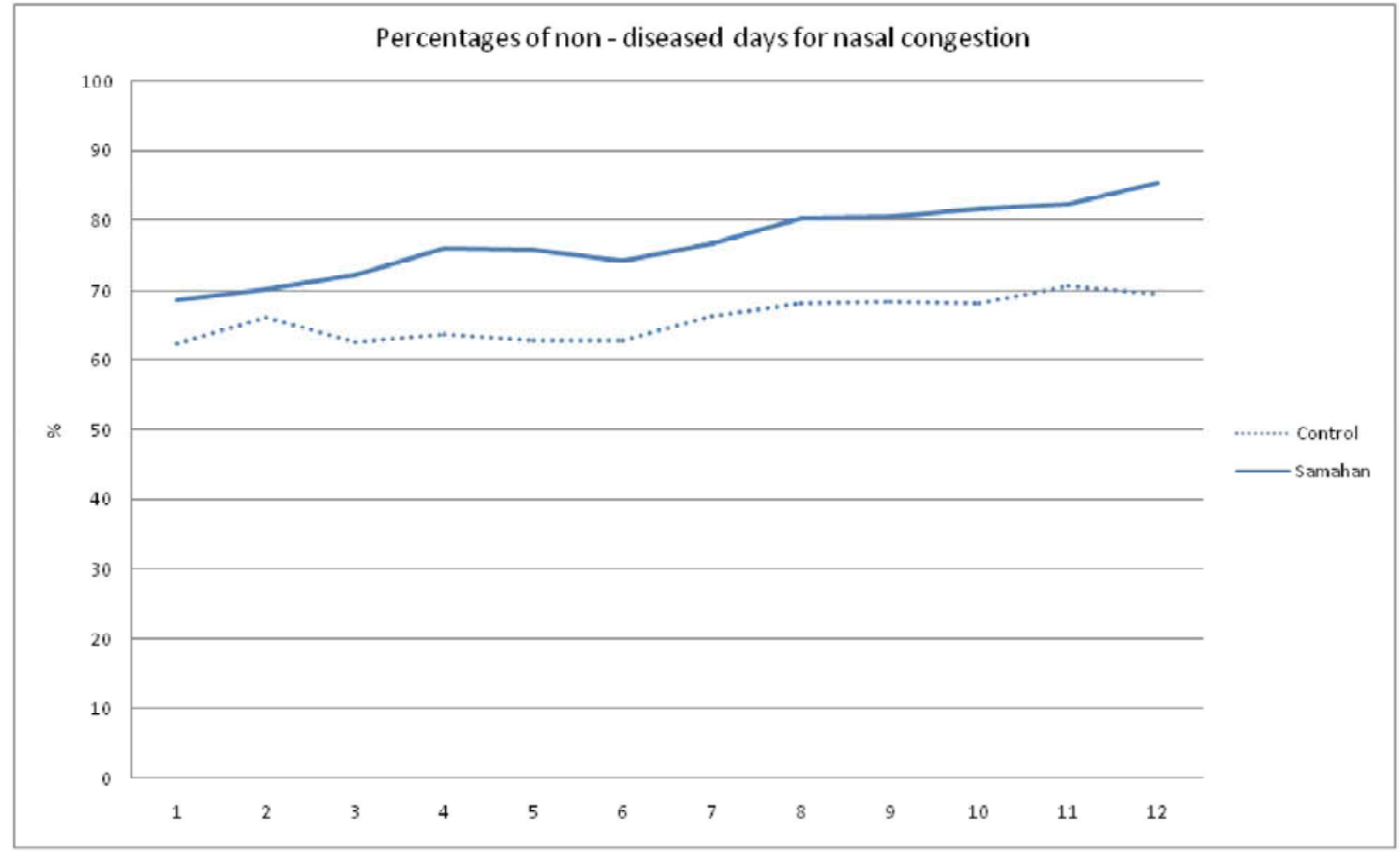

Figure 5. Percentage of days with no nasal congestion over time for the two groups.

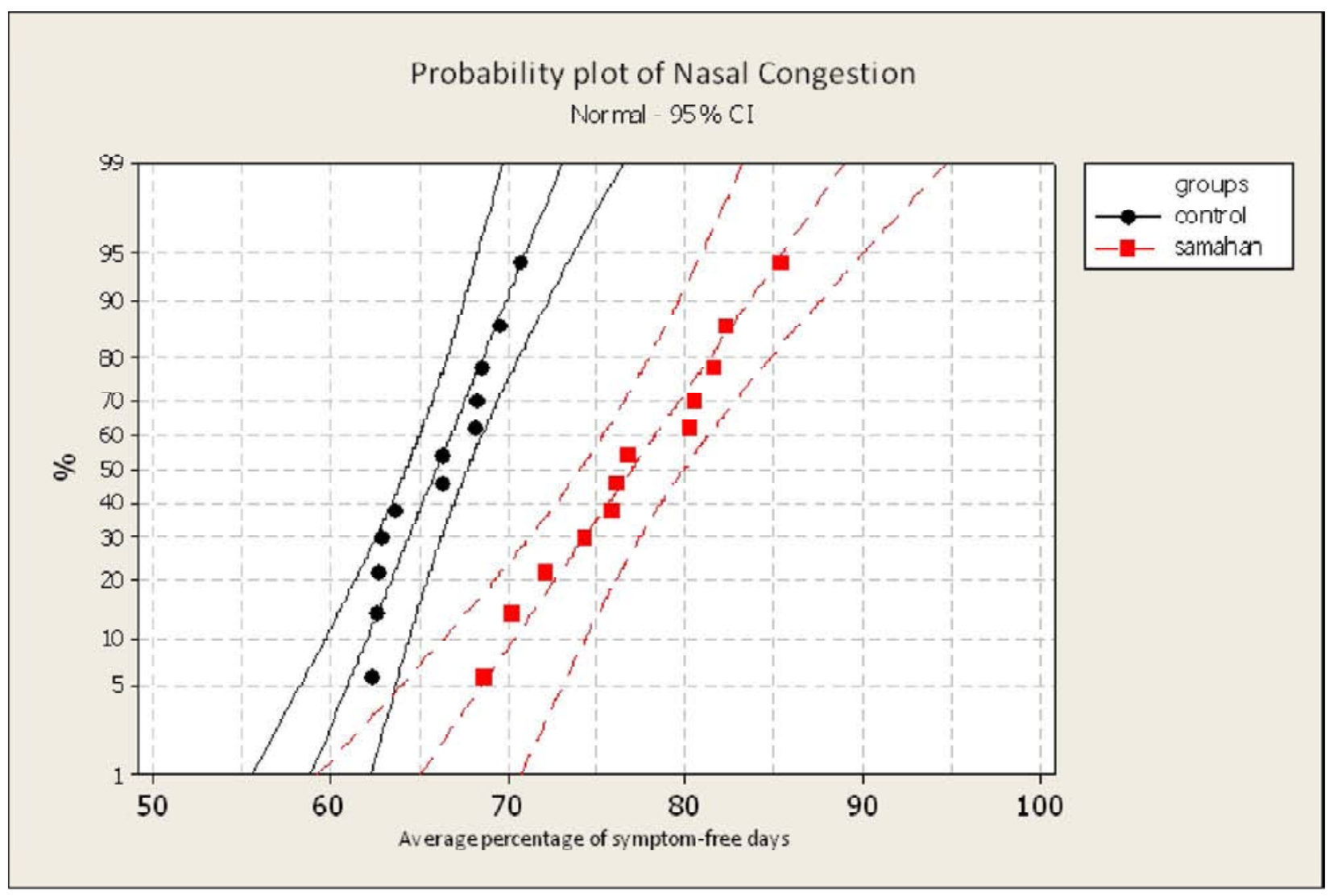

Figure 9. Normal probability plot for nasal congestion for the two groups. 


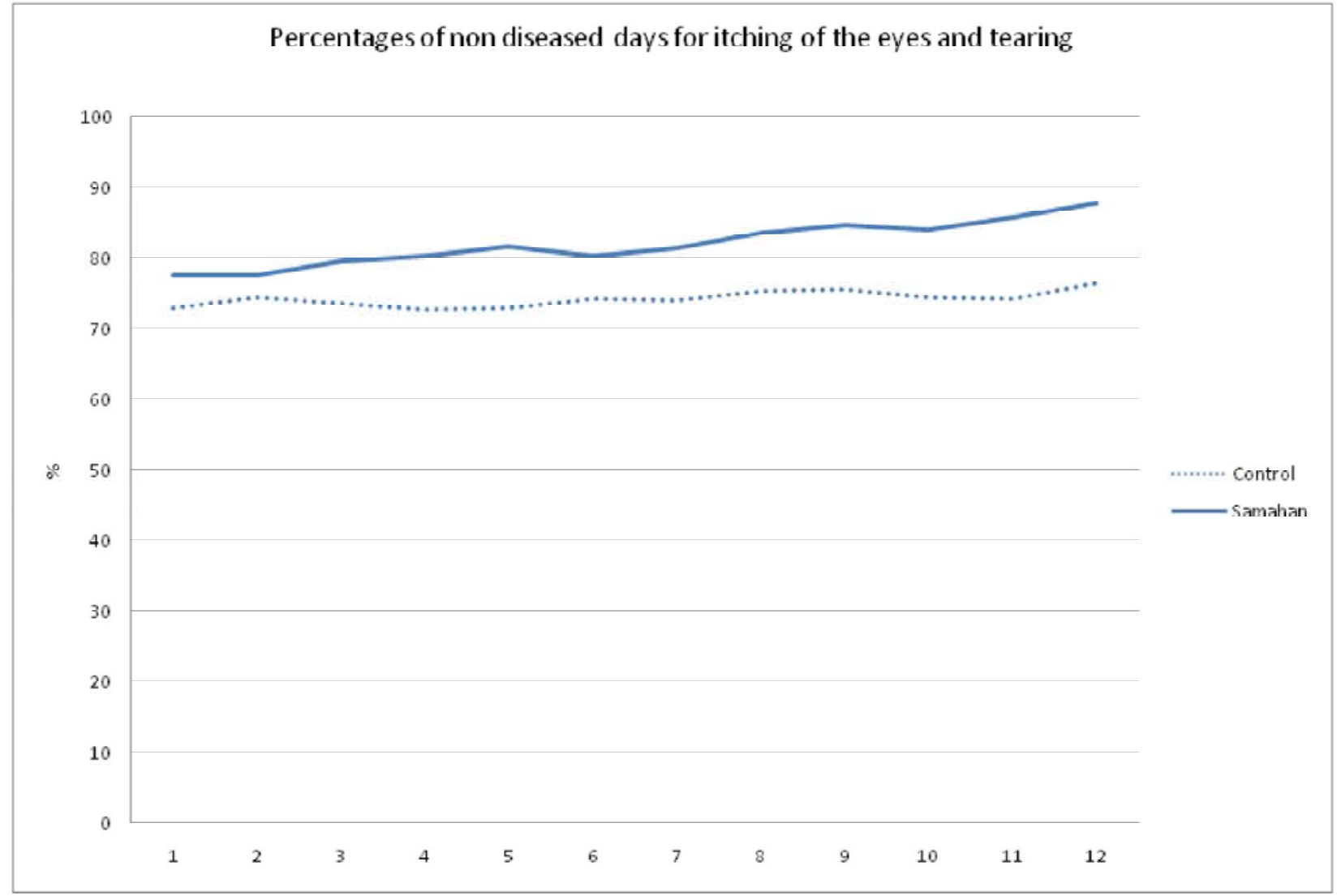

Figure 6. Percentage of days with no itching of the eyes and tearing over time for the two groups.

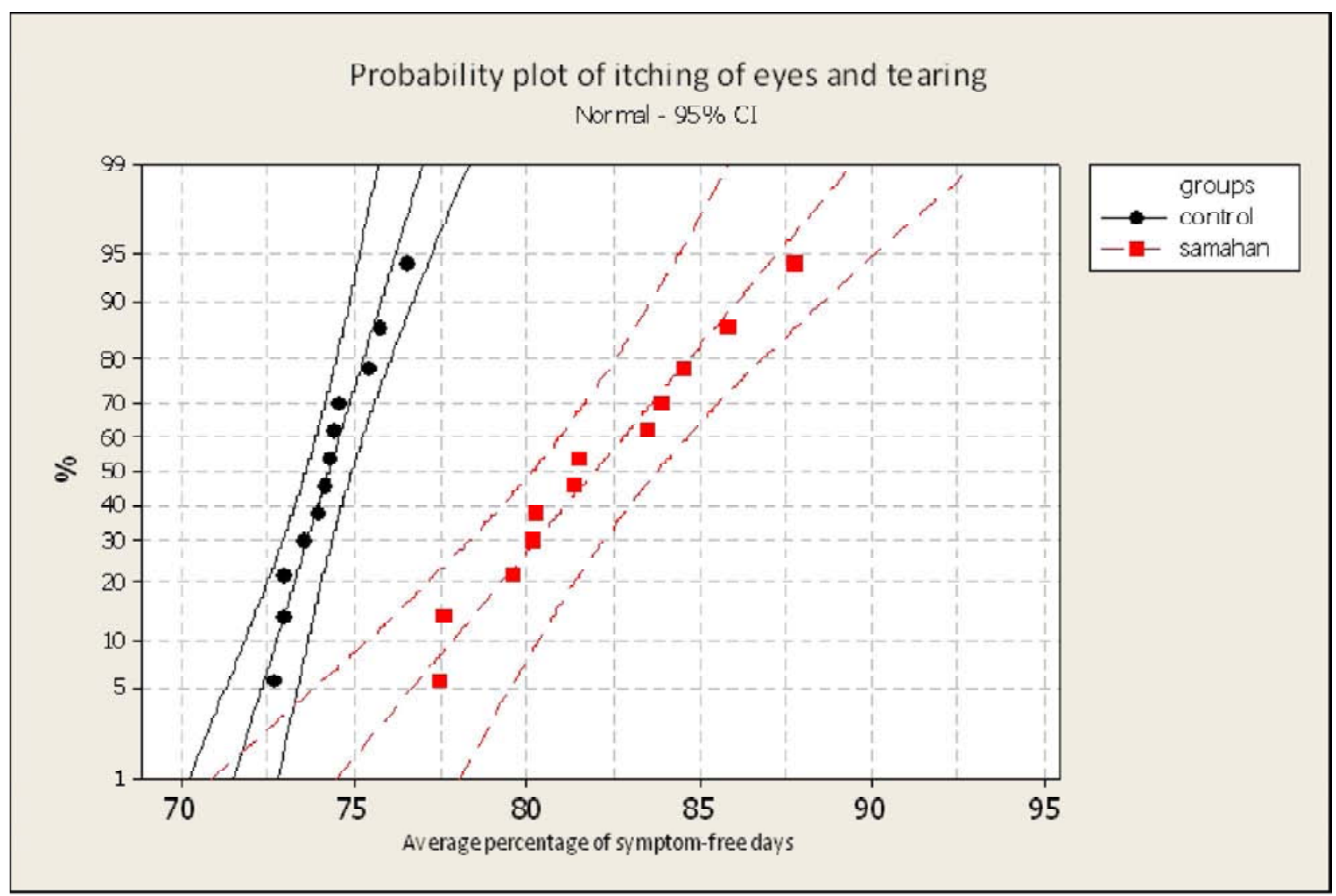

Figure 10. Normal probability plot for itching of eyes and tearing for the two groups. 


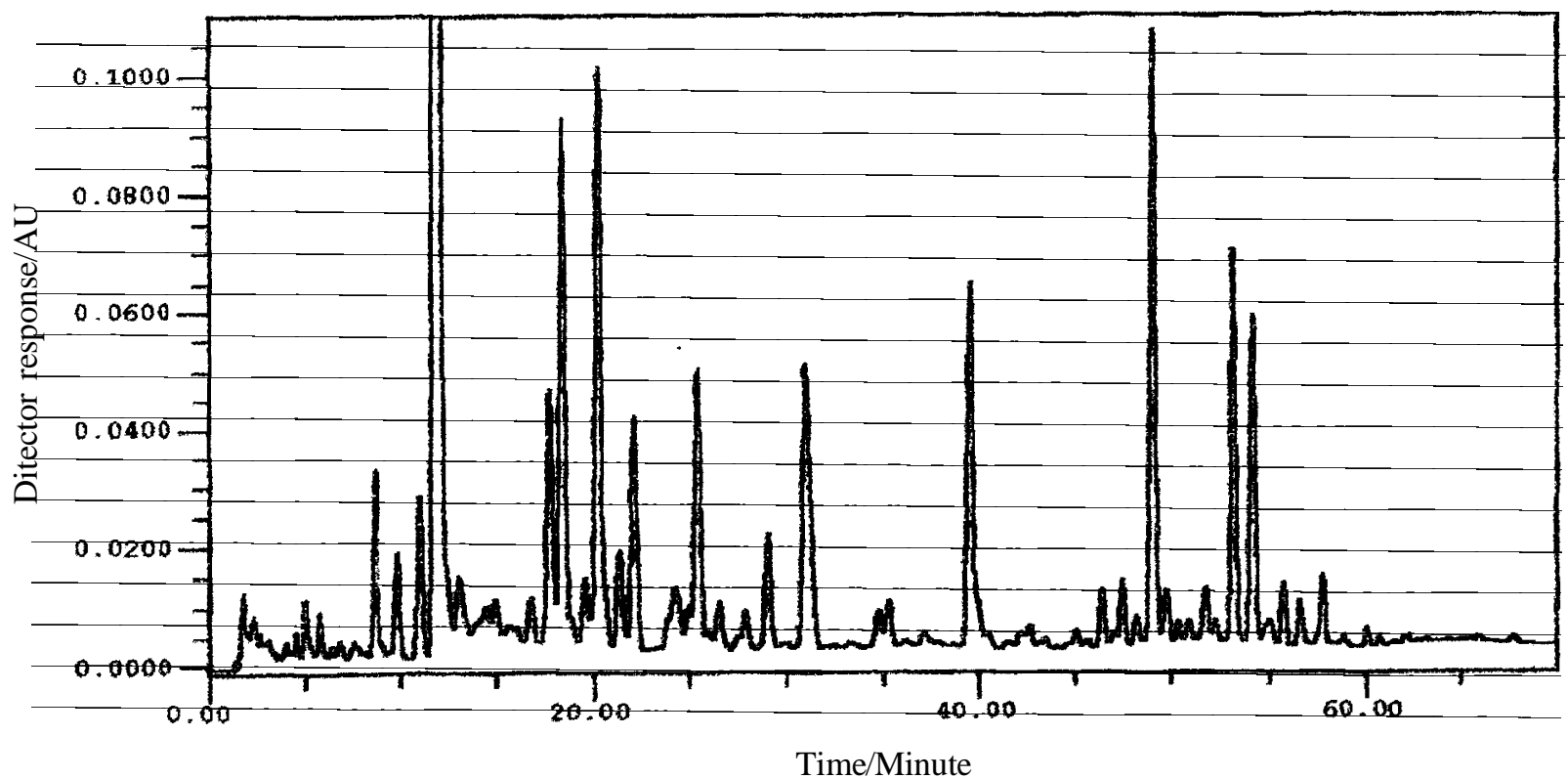

Column: Eclipse XDB -C18 (4.6×150 mm), Detector wavelength: 254 nm, Mobile phase: methanol/water, linear gradient.

Figure 11. High performance liquid chromatography (HPLC) fingerprint of Link Samahan ${ }^{\circledR}$.

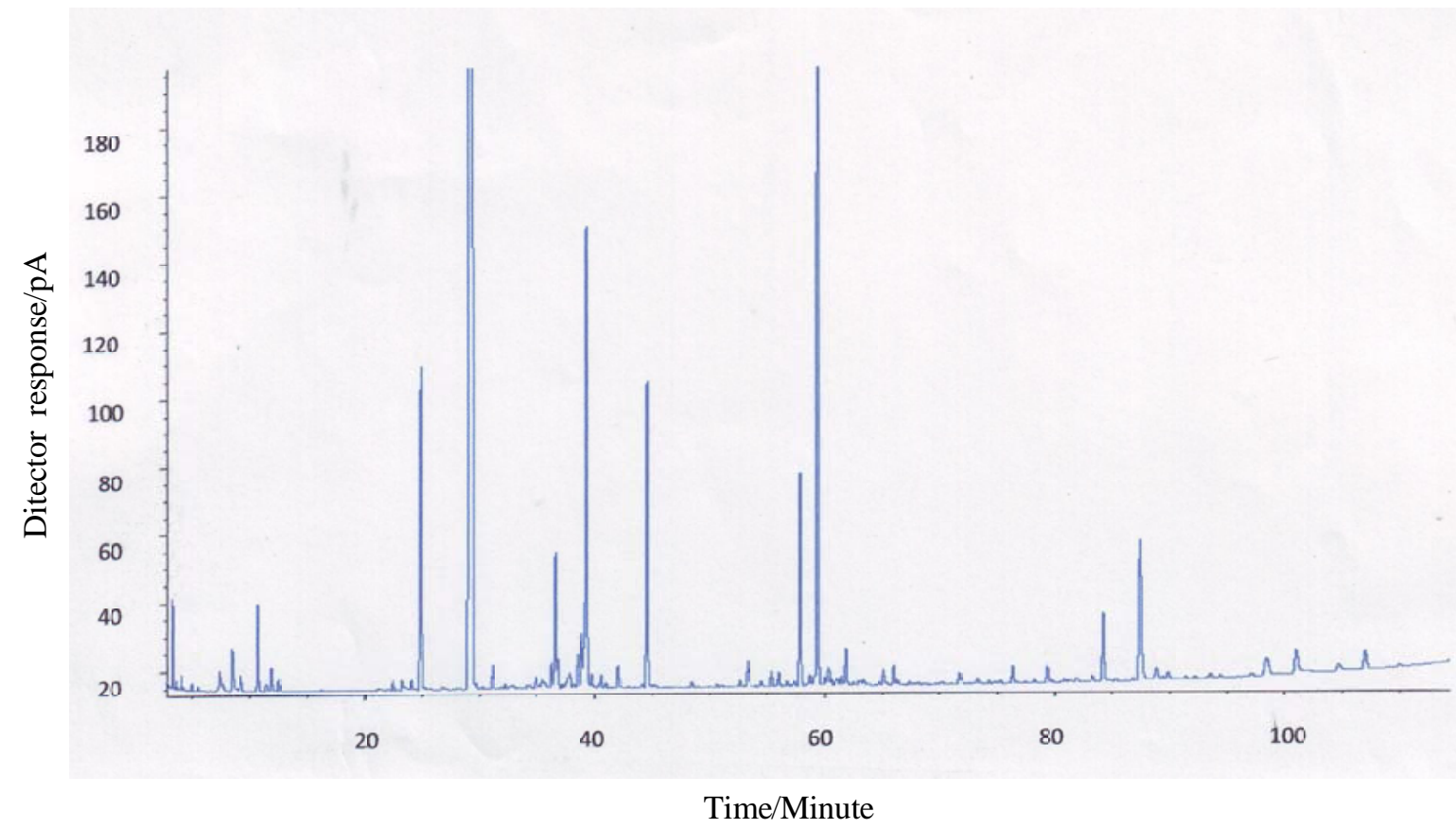

Column:DB-WAX capillary $(30 \mathrm{~m} \times 0.32 \mathrm{~mm}$, id 0.25$) \mu \mathrm{m}$ film, Temperature programme: $35^{\circ} \mathrm{C}$ to $225^{\circ} \mathrm{C}$, Detector: FID

Figure 12. Gas liquid chromatography (GLC) fingerprint of Link Samahan ${ }^{\circledR}$. 


\section{Results}

A total of 1020 healthy adult volunteers who initially volunteered to participate in our clinical trial were randomised to a test group $(n=506)$ and a control group $(n=514)$ after obtaining informed consent. However, only 956 volunteers (test group $n=465$, control group $n=491$ ) actually started participation. Visual scanning at the end of the trial revealed that 79 participants from the test group and 76 from the control group had not filled the forms properly for varying periods, and had to be excluded from final analysis, so only 386 from the test and 415 from the control group were taken for data entry and statistical analysis.

The mean ages of the test group $(29.5 \pm 7.7$ years $)$ and the control group $(29.7 \pm 7.9$ years $)$ were closely similar. The preponderance of women in both groups (test group $89.8 \%$, control group $91.2 \%$ ), is merely a reflection of their extremely high proportion (approximately $90.2 \%$ ) in the entire workforce.

MAS Linea Aqua, a factory producing swimwear for export, was selected for our trial for several relevant reasons. It employs a committed, highly productivityoriented workforce of over 3000, its working environment is tightly regulated for ambient temperature, relative humidity and laminar airflow (thus minimising environmental variables during working time of participants), its high ethical standards regarding workforce welfare, and convenience for monitoring herbal test product intake daily and for collecting the purposedesigned forms during a 84-day period of both groups.

The intake of the test herbal product by the appropriate group of participants was supervised daily by trained science graduates of our research team. They also supervised gathering the relevant data collection forms weekly from the participants. All participants were allocated a distinctive number at the point of randomisation, which was printed on the data collection forms given to them. This number was known to and its confidentiality was protected by, one science graduate member of the research team, who played no further role in the clinical trial except for separating the collected forms to each group for the purpose of data entry.

At the study's conclusion the average incidence of upper respiratory symptoms, estimated as described above, in the test group showed highly significant reductions at $p<0.0001$ for 6 symptoms and at $p<0.005$ for 3 symptoms, and a significant reduction $(p<0.05)$ for the remaining 6 (Table 2), when compared to the control group.

Table 2. Comparison of average incidence

\begin{tabular}{|c|c|c|c|c|}
\hline Symptom * & $\begin{array}{l}\text { Estimate for } \\
\text { difference in } \\
\text { incidence } \\
\text { (Control - Samahan) }\end{array}$ & $\begin{array}{l}95 \% \text { confidence } \\
\text { interval for difference } \\
\text { in incidence } \\
\text { (Control - Samahan) }\end{array}$ & Zvalue & Pvalue \\
\hline Excessive sneezing (1) & 0.214227 & $(0.274952,0.153502)$ & 6.091 & $<0.001$ \\
\hline Body pains (14) & 0.152330 & $(0.219835,0.0848262)$ & 4.042 & $<0.001$ \\
\hline Difficulties in daily activities (15) & 0.120138 & $(0.183383,0.0568933)$ & 3.72 & $<0.001$ \\
\hline Headache (11) & 0.118053 & $(0.184354,0.0517507)$ & 3.49 & $<0.001$ \\
\hline Tiredness (10) & 0.113019 & $(0.178663,0.0473757)$ & 3.37 & $<0.001$ \\
\hline Nasal congestion (3) & 0.106879 & $(0.169676,0.0440811)$ & 3.34 & $<0.001$ \\
\hline Watery nasal discharge (2) & 0.0906735 & $(0.153244,0.0281028)$ & 2.84 & 0.005 \\
\hline Throat pains (6) & 0.0843387 & $(0.142736,0.0259386)$ & 2.83 & 0.005 \\
\hline Itching of the throat (5) & 0.0840087 & $(0.142594,0.0254230)$ & 2.81 & 0.005 \\
\hline Loss of appetite (13) & 0.0808508 & $(0.141356,0.0203452)$ & 2.62 & 0.009 \\
\hline Cough (9) & 0.0804254 & $(0.143134,0.0177166)$ & 2.51 & 0.012 \\
\hline Itching and blocking of the ears (12) & 0.0749943 & $(0.133643,0.0163454)$ & 2.51 & 0.012 \\
\hline Hoarseness of voice (7) & 0.0684705 & $(0.124039,0.0129024)$ & 2.42 & 0.016 \\
\hline Feverishness (8) & 0.0597663 & $(0.109507,0.0100257)$ & 2.36 & 0.019 \\
\hline Itching of the eyes and tearing (4) & 0.0695622 & $(0.127650,0.0114749)$ & 2.35 & 0.019 \\
\hline
\end{tabular}

\footnotetext{
* The number in parentheses in the symptoms column corresponds to those shown in table 1.
} 
Table 3. Incidence over time

\begin{tabular}{|c|c|c|c|}
\hline Symptom* & $\begin{array}{l}\text { Least squares } \\
\text { mean of \% of } \\
\text { symptom free } \\
\text { days over time } \\
\text { (Control Group) }\end{array}$ & $\begin{array}{l}\text { Least squares } \\
\text { mean of \% of } \\
\text { symptom free } \\
\text { days over time } \\
\text { (Samahan Group) }\end{array}$ & $P$ value \\
\hline Itching of the eyes and tearing (4) & 73.1 & 77.2 & $<0.0001$ \\
\hline Headache (11) & 54.5 & 61.9 & $<0.0001$ \\
\hline Itching and blocking of the ears (12) & 72.3 & 76.6 & 0.0003 \\
\hline Watery nasal discharge (2) & 64.3 & 69.9 & 0.0004 \\
\hline Cough (9) & 63.7 & 68.2 & 0.0004 \\
\hline Excessive sneezing (1) & 67.0 & 70.5 & 0.0006 \\
\hline Nasal congestion (3) & 61.8 & 69.4 & 0.0012 \\
\hline Tiredness (10) & 56.5 & 63.4 & 0.0022 \\
\hline Itching of the throat (5) & 69.1 & 75.5 & 0.0023 \\
\hline Hoarseness of voice (7) & 75.9 & 80.7 & 0.0077 \\
\hline Feverishness (8) & 83.7 & 88.3 & 0.0124 \\
\hline Loss of appetite (13) & 68.6 & 74.7 & 0.0357 \\
\hline Throat pains (6) & 70.1 & 77.5 & 0.0472 \\
\hline Difficulties in daily activities (15) & 63.6 & 73.8 & 0.0517 \\
\hline Body pains (14) & 48.6 & 61.0 & 0.0578 \\
\hline
\end{tabular}

* The number in parentheses in the symptoms column corresponds to those shown in table 1.

Table 4. Comparison of average severity

\begin{tabular}{|c|c|c|c|c|c|}
\hline Symptom & $\begin{array}{l}\text { Improvement } \\
\text { Category }\end{array}$ & $\begin{array}{l}\text { Estimate of } \\
\text { severity (vs no } \\
\text { symptoms), } \\
\text { Control - Samahan }\end{array}$ & $\begin{array}{l}95 \% \text { confidence } \\
\text { interval for } \\
\text { difference in } \\
\text { severity (Control - } \\
\text { Samahan) }\end{array}$ & $Z$ value & P-Value \\
\hline Excessive sneezing & Severe & 0.477010 & $\begin{array}{l}(0.532989, \\
0.421031)\end{array}$ & 16.70 & $<0.001$ \\
\hline Nasal discharge & NS & NS & NS & NS & NS \\
\hline Nasal congestion & NS & NS & NS & NS & NS \\
\hline Itching and tearing eyes & NS & NS & NS & NS & NS \\
\hline Itching of the throat & Mild & 0.0539721 & $\begin{array}{l}(0.106497 \\
0.00144698)\end{array}$ & 2.00 & 0.046 \\
\hline Throat pain & Mild & 0.541667 & $\begin{array}{l}(0.106389, \\
0.00194428\end{array}$ & 2.02 & 0.044 \\
\hline
\end{tabular}




\begin{tabular}{|c|c|c|c|c|c|}
\hline Symptom & $\begin{array}{l}\text { Improvement } \\
\text { Category }\end{array}$ & $\begin{array}{l}\text { Estimate of } \\
\text { severity (vs no } \\
\text { symptoms), } \\
\text { Control - Samahan }\end{array}$ & $\begin{array}{l}\text { 95\% confidence } \\
\text { interval for } \\
\text { difference in } \\
\text { severity (Control - } \\
\text { Samahan) }\end{array}$ & Zvalue & $P$ Value \\
\hline Hoaseness of voice & Moderate & 0.0433296 & $\begin{array}{l}0.0821080 \\
0.00455109)\end{array}$ & 2.16 & 0.030 \\
\hline Fever & NS & NS & NS & NS & NS \\
\hline Cough & NS & NS & NS & NS & NS \\
\hline Tiredness & NS & NS & NS & NS & NS \\
\hline Headache & NS & NS & NS & NS & NS \\
\hline Itching and blocking ears & NS & NS & NS & NS & NS \\
\hline Loss of appetite & NS & NS & NS & NS & NS \\
\hline Body pains & Mild & 0.0690449 & $\begin{array}{l}(0.130484, \\
0.00760612)\end{array}$ & 2.19 & 0.029 \\
\hline Difficulties in daily activitie & Severe & 0.0519955 & $\begin{array}{l}(0.0940458 \\
0.00994519)\end{array}$ & 2.39 & 0.017 \\
\hline
\end{tabular}

NS - not significant

Table 5. Severity analysis

\begin{tabular}{ll}
\hline Symptom & Severity result \\
\hline Excessive sneezing & Severe category improvement \\
Nasal discharge & No improvement \\
Nasal congestion & No improvement \\
Itching and tearing eyes & No improvement \\
Itching of the throat & Mild category improvement \\
Throat pains & Mild category improvement \\
Hoaseness of voice & Moderate category improvement \\
Fever & No improvement \\
Cough & No improvement \\
Tiredness & No improvement \\
Headache & Mild category improvement \\
Itching and blocking ears & No improvement \\
Loss of appetite & No improvement \\
Body pains & Mild category improvement \\
Difficulties in daily activities & Severe category improvement \\
\hline
\end{tabular}


The results of our model-based test [4] indicated that except for 2 symptoms (viz. difficulties in daily activities and body pains), the test herbal product showed a highly significant reduction over time at $p<0.0001$ for 2 symptoms and at $p<0.005$ for 7 symptoms, and a significant reduction $(<0.05)$ for 4 symptoms, during the entire study duration (Table 3 ) in the test group when compared to the control group.

Severity of symptoms as assessed by participants on a scale of $0,1,2$ and 3 (Figure 1), and estimated statistically as detailed earlier, also showed a significant reduction $(p<0.05)$ for 7 symptoms, and a reduction of the other 8 symptoms too on descriptive analysis, though the latter were not significant at the 5\% level (Tables 4 and 5), when the test group was compared to the control group.

The high performance liquid chromatography and gas liquid chromatography fingerprints of Link Samahan ${ }^{\circledR}$, which are just two of the battery of quality assurance tests routinely performed during the manufacturing process and of the finished product, are given in Figures 11 and 12.

\section{Discussion}

Our study compared the effect of taking one sachet daily of a herbal product in hot water for 84 consecutive days, on 15 upper respiratory symptoms, previously validated for reliability, responsiveness, importance to patients, and convergence with other measures, in a cohort of healthy volunteers (test group, $\mathrm{n}=465$ ), with a similar cohort taking only plain tea at approximately the same time of day (control group, $n=491$ ), both cohorts being derived from a total of 1020 volunteers by random allocation to each group [1,2].

The herbal product we have tested has been registered by the Department of Ayurveda (Registration number 02/01/PD/08/148). It has been in use extensively locally as well as in foreign countries for over 15 years as an over-the-counter convenient preparation for upper respiratory tract ailments with catarrhal symptoms. However, its putative efficacy in reducing the incidence and severity of upper respiratory symptoms had not been tested in a clinical trial before our study.

The test herbal product is an extract of 14 medicinal herbs: Adhatoda vasica (root [5]), Alpinia galanga (rhizome [6]), Carum copticum (seed [7]), Coriandrum sativum (seed [8]), Coscinium fenestratum (stem [9]), Cuminum cyminum (seed [10]), Evolvulus alsinoides (whole plant [11]), Glycyrrhiza glabra (root [12]), Hedyotis corymbosa (whole plant [13]), Piper longum (fruit [14]), Piper nigrum (fruit [15]), Premna herbacea (root [16]), Solanum xanthocarpum (whole plant [17]), and Zingiber officinale (rhizome [18]).

From the large number of references available for the efficacy and the probable pharmacologic basis for beneficial effects of individual components, we have here quoted only one for each. However, it needs to be emphasized that we have performed an extensive literature survey to exclude with confidence the possibility of adverse effects of all 14 plants.

Seminal WHO recommendations for evaluation of herbal medicinal products, while noting the importance of robust research and encouraging clinical trials, has observed that these medicines may be regarded as a rich source of potentially useful therapies, and that actual benefits remain to be identified by clinical trials conforming to modern principles of clinical research [19]. The WHO guidelines specifically state also that substantial prior human use of traditional herbal substances or products conveys reasonable confidence that they can be administered safely in clinical trials, and that clinical evaluation does not require purification of the herbal medicinal products to single chemical constituents, because the mixture of uncharacterised constituents provides the postulated unique additive or synergistic advantage of herbal medicines [19]. In a nutshell these WHO recommendations comprise the justification for our study.

The literature survey that we conducted indicated that the plants used in the manufacture of the product we have tested have anti-pyretic (eg. Premna herbacea, Zingiber officinale), anti-inflammatory (eg. Hedyotis corymbosa, Piper nigrum), anti-bacterial (eg. Alpinia galanga, Coriandrum sativum), anti-viral (eg. Cuminum cyminum), anti-allergic (eg. Glycyrrhiza glabra), expectorant (eg. Solanum xanthocarpum, Evolvulus alsinoides), anti-spasmodic (eg. Carum copticum, Coscinium fenestratum), and anti-tussive (eg. Zingiber officinale, Solanum xanthocarpum) activity that are likely to relieve upper respiratory symptoms, commonly referred to as catarrh, associated with viral, bacterial or allergic upper respiratory inflammation [5 - 18, 20]. Of particular interest were reports that several of these herbs (eg. Adhatoda vasica, Piper longum, Piper nigrum, Zingiber officinale) have immune-stimulatory actions, which are likely to diminish the incidence of episodic upper respiratory inflammation. Hence our study protocol was designed to investigate average incidence, incidence over time, and a severity assessment by participants, of incidents of upper respiratory symptoms over 84 consecutive days while taking one sachet daily of the test herbal product, compared to a similar group not taking the test herbal product.

We have tried, as far as is practically possible, to conform to the accepted principles of randomisation and blinding [21]. In our clinical trial, the principal investigators, trained data entry form collectors, trained data entry operators, and consultant statisticians who performed the analyses were blinded to the identity of the group to which volunteer participants belonged, until after the results of all statistical analyses were completed [22].

However, it was impossible to formulate a suitable placebo for the test product because of its characteristic aroma, as we have indicated above. As a consequence, the control group participants took plain tea, instead of the test product dissolved in hot water at about the same 
time of day as the test group. Insuperable problems of "blinding" in certain clinical trials has been discussed in detail by experts in the field, but no statistically acceptable solution is available for dissociating a possible placebo effect in such trials as the present one [21, 22]. Since participants in both test and control groups in our study assessed severity of the 15 selected symptoms, awareness of a possible "placebo effect" in the former assumes importance in interpretation of the results.

\section{Conclusions}

In a substantial sample of 386 healthy adults working in a highly productivity-oriented garment factory producing swimwear for export who took one sachet of the test herbal product in warm water daily, the results of our study show a significant reduction in the average incidence of all 15 upper respiratory symptoms selected from a group of 21 symptoms previously validated in community surveys, a significant reduction of 13 symptoms over time, and a significant reduction in participant-assessed severity of 7 symptoms with a nonsignificant reduction of the other 8 , when compared to a cohort of 415 who did not take the test herbal product $[1,2]$. Taken together these results show the effectiveness of the test herbal product, and its benefits in reducing incidence, incidence over time and severity of the 15 upper respiratory symptoms.

The results of our study warrant the extension of clinical trials of this herbal product to patients who suffer from conditions such as seasonal or perennial rhinitis and conjunctivitis. Our results indicate yet another dimension for investigation, i.e. the probable effects of the herbal product in curbing absenteeism and increasing output among employees in highly productivity-oriented industries by reducing incidence and severity of troublesome upper respiratory symptoms.

\section{Acknowledgements}

Link Natural Products (Pvt) Ltd provided funding for the entire study. We thank the management of MAS Linea Aqua for agreeing to provide access and optimum facilities for our study, and all the employees of the factory who cooperated cheerfully with us during the lengthy period of our clinical trial.

\section{References}

1. Barett B, Brown R, Mundt M, et al. The Wisconsin Upper Respiratory Survey is responsive, reliable and valid. Journal of Clinical Epidemiology 2005; 58: 609-17.

2. Barrett B, Brown RL, Mundt MP, et al. Validation of the short form Wisconsin Upper Respiratory Symptom Survey (WURSS-21). Health and Quality of Life Outcomes 2009; 7: 76-96.

3. Pocock SJ. Clinical Trials. A Practical Approach. Wiley, Chichester, 1983.

4. Graybill FA. Theory and Applications of the Linear Model. Duxberry Press, London, 1996.
5. Jayant ND. Anti-tussive effect of Adhatoda vasica extract on mechanical or chemical stimulation-induced coughing in animals. Journal of Ethnopharmacology 1999; 67: 361-5.

6. Inamdar MC, Khorana ML, Rajaram MR. Expectorant activity of Alpinia galanga. Indian Journal of Physiology and Pharmacology 1962; 6: 150-3.

7. Boskabady MH, Jandaghi P, Kiani S, Hasanzadeh L. Antitussive effect of Carum copticum in guinea pigs. Journal of Ethnopharmacology 2005; 97: 79-82.

8. Sonika G, Manubala R, Deepak J. Comparative studies on anti-inflammatory activity of Coriandrum sativum, Datura strammonium and Azadirachta indica. Asian Journal of Experimental Biological Sciences 2010; 1: 151-4.

9. Nair GM, Narasimhan S, Shiburaj S, Abraham TK. Antibacterial effects of Coscinium fenestratum. Fitoterapia 2005; 76: 585-7.

10. Boskabady MH, Kiani S, Azizi H. Relaxant effect of Cuminum cymimum on guinea pig tracheal chains and its possible mechanisms. Indian Journal of Pharmacology 2005; 37: 111-5.

11. Ganju L, Chanda S, Srivastava KK, Sawhney RC, Selvamurthy W. Immunomodulatory effects of agents of plant origin. Biomedicine and Pharmacotherapy 2003; 57: 296-300.

12. Marjan NA, Hossein H. Review of pharmacological effects of Glycyrrhiza spp and its bioactive compounds. Phytotherapy Research 2008; 22: 709-24.

13. Saskumar JM, Maheshu V, Bell GS, Priyadarshani DT. In vitro antioxidant activity of Hedyotis corymbosa, aerial parts. Indian Journal of Biochemistry and Biophysics 2010; 47: 4952.

14. Dahanukar SA, Karandikar SM, Desai M. Efficacy of Piper longum in childhood asthma. Indian Drugs 1984; 21: 384-8.

15. Seung HK, Young CL. Piperine inhibits eosinophil infiltration and airway hyper-responsiveness by suppressing $\mathrm{T}$ cell activity and cytokine production in the ovalbumin-induced asthma model. Journal of Pharmacy and Pharmacology2009; 61: 353-9.

16. Narayan $\mathrm{N}$, Thirugnanasambanthan $\mathrm{P}$, Viswanathan $\mathrm{S}$, et al. Antipyretic, antinociceptive and anti-inflammatory activity of Premna herbecea. Fitoterapia 2000; 71: 147-53.

17. Govindan S, Viswanathan S, Vijayasekaran V, Alagappan R. Further studies on the clinical efficacy of Solanum xanthocarpum and Solanum trilobatum. Phytotherapy Research 2004; 18: 805-9.

18. Hamid R, Forouzan G, Hamid N. Effects of ginger on the improvement of asthma: an evaluation of its treatment effects. Pakistan Journal of Nutrition 2006; 5: 373-6.

19. UNICEF/UNDP/WORLD BANK/WHO Special Programme for Research and Training in Tropical Diseases. Operational guidance: information needed to support clinical trials of herbal products. TDR/GEN/GUIDANCE/05.1. WHO, Geneva, Switzerland, 2005.

20. Menike AMSC. A study of the chemistry and technology of Ayurvedic preparations. PhD Thesis, University of Sri Jayewardenepura, 1995.

21. Schulz KF, Grimes DA. Blinding in randomised trials: hiding who got what. Lancet 2002; 359: 696-700.

22. Schulz KF, Chalmers I, Altman DG. The landscape and lexicon of blinding in randomised trials. Annals of Internal Medicine 2002; 136: 254-9. 